\title{
COMPARATIVE PHYSIOLOGICAL AND BODY COMPOSITION PARAMETERS IN TEAM SPORTS AND SPRINT TRAINED INDIAN ATHLETES
}

\author{
Subhojit Chatterjee $^{1}$, Usra Hasan ${ }^{2}$, Subhra Chatterjee ${ }^{1^{*}}$ \\ ${ }^{1}$ Sports Authority of India, Human Performance Laboratory, \\ New Delhi, India \\ ${ }^{2}$ Department of Physiology, School of Allied Health Sciences, \\ Sharda University, New Delhi, India
}

\begin{abstract}
Introduction: Physiological and body composition variables have important role for assessment of training status and evaluation of health status of athletes. Regular monitoring of these variables during training may provide valuable information to coaches for training and selection of players' training protocol participating in both team sports and individual events.

Purpose and objectives of the study: The aims of this study were to compare physiological and body composition variables between male athletes participating in team sports (football) and individual sprint event and also to correlate training duration (both in years and hours per week) of male athletes participating in both team sports as well as sprint with physiological and body composition variables.

Applied Methodology: The study was carried out with thirty-year-old $(n=30)$ and BMI matching male Indian athletes participating in team sports (football, $n=16)$ and individual sprint event $(n=14)$, having minimum 2 years of official training. They were in post competitive phase during the test. Several physiological and body composition variables were assessed such as height, weight, body mass index, training age (years), training time (hours/week), fat mass, fat-free mass, body cell mass, muscle mass, $V O$, max, maximal power, training intensity atigue index following standard protocol.

Achieved major results: The sprinters were found to possess significantly more fat free mass $(p<.01)$, body cell mass $(p<.01)$, muscle mass $(p<.01)$, less fat mass $(p<.05)$ and more average anaerobic power $(p<.01)$ than their peers - football players. However, no significant correlation was found between any of the measured physiological and body composition parameters and the training status of these players.

Conclusion: This study would provide useful information for assigning training protocols to the athletes participating in team sports and individual sprint events on the basis of physiological and body composition parameters.
\end{abstract}

OPEN ACCESS

Submitted: 11 February 202 Revised: 19 April 2021 Accepted: 12 May 2021

ORCID iD

Subhojit Chatterjee: https://orcid.org/0000-0002-3789-1658 Usra Hasan: https://orcid.org/0000-0002-5375-5525 Subhra Chatterjee: https://orcid.org/0000-0002-2583-551X

Cite this article as: Chatterjee, S., Hasan, U., Chatterjee, S. (2021).

Comparative physiological and body composition parameters in team sports and sprint trained indian athletes Journal of Applied Sports Sciences, Vol.1, DOI: $10.37393 /$ JASS. 2021.01 .1

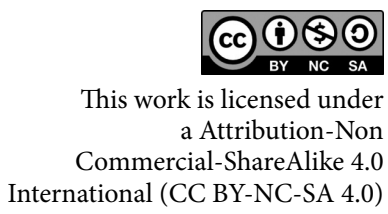

This work is licensed under a Attribution-Non Commercial-ShareAlike 4.0 International (CC BY-NC-SA 4.0)

\section{INTRODUCTION}

Every sportsman or nation wants to show their dominance by challenging other nations by showing supremacy in sporting performance in international competitions. Thus this challenge excites, inspires and motivates all the nations to sweat and struggle to run faster, jump higher, throw far and display greater strength, endurance and skills in present compe-
Key words: football, sprint event, training status, anaerobic power, fatigue index titive sports world. This can only be achievable through scientific, systematic and planned sports training by channeling them into suitable games and sports and finding out their potentialities.

Individual sport athletes practice in groups or individually. They compete individually and have individual results, which can be part of a team result. Team sport athletes practice mostly 
in groups and they compete with a team and the team shares the results (Lindwall et al., 2002). To develop the most effective training program, it is important that the coach know and be aware of the physiological demands the athlete experiences during competition. Most team sports (e.g. basketball, football, hockey, rugby, volleyball) can be described as moderate-to-long duration exercise including repeated bouts of high-intensity activity combined with periods of low-to-moderate active recovery or passive rest. Players' capability to execute repeated sprints with short duration recovery in between is an important determinant of performance in intermittent team sports (Spencer et al., 2005; Rampinini et al., 2007). This activity pattern determines to a great extent the physiological necessities of team sports. This is in contrast to coaches training individual sports athletes, such as sprinters, who generally perform a separate event requiring maximal effort. The physiological demands imposed on those athletes are easier to be aware of; consequently, the design of their training program is more clear-cut. The training program for the sprinter is focused primarily on developing power, improving running technique and speed and increasing speed endurance. Also, the training program for the sprinter is unlike that of the football player, whose primary emphasis during anaerobic conditioning is to get ready for repeated bouts of high intensity activity with limited rest intervals. In contrast, the sprinter's training program is less concerned with improving fatigue rate and more concerned with the quality of each sprint.

Numerous studies have been carried out to analyze the effect of training on various body composition and physiological parameters, having an impact on performance of athletes from different sports (Charmas, Gromisz., 2019; Genc et al., 2019; Manna et al., 2010). Physiological and body composition variables have important role for assessment of training status and evaluation of health and cardiovascular status of athletes. Regular monitoring of these variables enables coaches to assess the current status of players participating in both team sports and individual events and the degree of their training adaptability and to formulate their training schedule accordingly to achieve the desired performance. However, studies on the physiological and body composition parameters of male athletes participating in both team sports and individual events specifically in relation to training are lacking in India. In view of this, this study was undertaken with the following aims:

1. To compare physiological and body composition variables between male athletes participating in team sports (football) and individual sprint event.

2. To correlate training status of male athletes participating in both team sports as well as sprint with selective physiological and body composition variables.

\section{METHODOLOGY}

\section{Ethical Statement}

The study was designed as a cross- sectional non invasive study. All experimental procedures were conducted in full accordance with the World Medical Association Declaration of Helsinki after taking permission from the Institutional Ethics Committee. A written informed consent was obtained as per declaration of Helsinki from all the athletes below the age of 18 years from the parents or guardians. Before taking the measurement, the players were instructed according to Heyward \& Stolarczyk (1996) by the following guidelines: 1 . No heavy exercise 12 hours before the test; 2 . No large meals an hour before the test and 3. Consumption of liquids limited to $1 \%$ of body weight or two $8 \mathrm{oz}$ glasses of water, 2 hours before the test.

\section{Subjects}

Thirty Indian male athletes with similar age group and body mass index (BMI) partic- 
ipating in individual sprint event $(\mathrm{n}=14)$ and team sports (footballers) $(\mathrm{n}=16)$ were selected for the study. An informed consent was taken from the subject prior to testing and protocol was clearly explained to them. They were selected from Come and Play Scheme of Sports Authority of India (SAI), Jawaharlal Nehru Stadium, New Delhi. The athletes had a history of participation in at least state level competitive events with minimum of 2 years formal training and were in post competitive phase during the conduction of the test. The players were reported to be training for at least 10 hours per week during the current season, were non-smokers, and none of them was taking any medication at the time of testing.

\section{Procedure}

All the subjects were evaluated for various physiological and body composition variables at Human Performance Laboratory, SAI and conducted during morning hours on similar day. They underwent body composition evaluation first and then sub maximal exercise testing with the help of bicycle ergometer after being familiarized with the exercise protocol, followed by a field test Running-Based Anaerobic Sprint Test (RAST). The subjects had a light meal at least 2 hours before the exercise test. Their medical history and training duration was assessed by a preset questionnaire.

The training was relatively common to all the participants of the study besides the skill training. Hours per week of sports training (hours/week) were self-reported by athletes and were concluded by multiplying training sessions in a week by hours per training session. Body weight and height were measured with the use of a scale (SECA GmBH \& Co. KG., Hamburg, Germany) to the nearest $0.1 \mathrm{~kg}$ and $0.1 \mathrm{~cm}$ respectively. BMI was calculated as the ratio of weight to height squared.

Body composition was measured with med- ical body composition analyzer (SECA mBCA model 515, Hamburg, Germany) which is an eight-electrode segmental multi frequency bioelectric impedance analyzer (MFBIA) that measures impedance at 19 different frequencies ranging from $1 \mathrm{kHz}$ to $1 \mathrm{MHz}$ under uniform and controlled laboratory conditions. It consisted of evaluation of body cell mass (BCM), fat free mass (FFM), fat mass (FM) and muscle mass (MM) of the athletes of both groups (Thurlow et al., 2018).

The subjects were asked to relax for 5 minutes, following which pre-exercise heart rate was recorded by observing the heart rate from Polar (H7) heart rate monitor (Aggarwala et al., 2018).

$\mathrm{VO}_{2}$ max was calculated with Astrand 6-minute sub-maximal protocol, on Cycle Ergometer (model Monark LC7TT, Sweden) (Aggarwala et al., 2018). This test was done by one individual at a time. Test protocol was explained to the subjects and it was ensured that they understood it clearly. The work intensity per session was gauged by heart rate monitor. Maximal heart rate (MHR) was calculated, and $75 \%$ of MHR was estimated for the protocol. Before the beginning of the test, the seat was adjusted with respect to the participant's height. This was followed by a 2-3 minuets warm-up without resistance. The participants were asked to maintain 60 cadences throughout the protocol. After 3 minutes, the load was increased to $75 \mathrm{~N}$ and the participant was asked to continue paddling. Once the heart rate was seen to be stabilizing, the load was increased to $100 \mathrm{~N}$ and later up to $125 \mathrm{~N}$ according to the capability of the participant. If the participant was not able to paddle any further, the load was decreased slightly. 'Astrand protocol' is a submaximal protocol for aerobic capacity assessment, therefore, $75 \%$ of MHR was calculated and it was ensured that the heart rate of participant was maintained within the calculated heart rate. The participants followed the protocol, and paddled for 6 minutes, 
however if the heart rate did not stabilize, the test was extended for another minute. After the complete protocol, participants were asked to continue paddling at $25 \mathrm{~N}$ loads with proper breathing, for next 3 minutes for cool down.

Average anaerobic power and fatigue index were determined by running based anaerobic sprint test (RAST). A $35 \mathrm{~m}$ long track was set. The participant was asked to reach the opposite end of the track, as fast as he could. Then, 10 second rest was given to the participant. The same procedure was repeated 6 times. The time was recorded with a stopwatch. Average anaerobic power and fatigue index were calculated by putting the values of each lap in the equation (Zagatto et al., 2009).

\section{Statistical Analysis}

All statistical analysis tests were performed with statistical package for social sciences (SPSS) version 20.0 (SPSS Inc., Chicago, IL, USA). The normality of the data was checked with Shapiro Wilk test. Difference between selected physiological and body composition variables among athletes participating in team sports and individual events were checked by applying parametric unpaired Student's $T$-test. Correlation between the selected variables was checked with Pearson's Correlation coefficient. The correlation coefficients $(r)$ were classified as very weak $(0.0$ $0.2)$, weak $(0.2-0.4)$, moderate $(0.4-0.7)$, strong $(0.7-0.9)$ or very strong $(0.9-1.0)$ in all cases (Akoglu, 2018). All the data were expressed as mean $\pm \mathrm{SD}$. Criterion alpha level of $p \leq .05$ was used to determine statistical significances.

\section{RESULTS}

The comparison of various body composition and physiological parameters between Indian male athletes participating in competitive team sports and individual events is depicted in Table 1. It was revealed that FFM, BCM, MM and anaerobic power were significantly higher in athletes participating in individual events than in the athletes participating in team sports $(p<.01)$. On the other hand, athletes participating in team sports had significantly more amount of fat mass than the athletes participating in individual events ( $p$ $<.05)$. The rest parameters were found to be altered in a statistically insignificant manner in both groups.

Table 1. Comparison of selective physiological and body composition variables among male athletes participating in team game and individual events with their significance level

\begin{tabular}{|c|c|c|c|c|}
\hline Nom. & Parameters & $\begin{array}{c}\text { Team game } \\
n=16\end{array}$ & $\begin{array}{c}\text { Individual event } \\
n=14\end{array}$ & $\begin{array}{l}\text { T value (level of } \\
\text { significance) }\end{array}$ \\
\hline 1. & Age (years) & $17.56 \pm 1.31$ & $17.57 \pm 1.86$ & $0.015^{.988}$ \\
\hline 2. & Height $(\mathrm{cm})$ & $171.13 \pm 5.65$ & $175.07 \pm 7.73$ & $1.576^{0.128}$ \\
\hline 3. & Weight (kg) & $58.81 \pm 6.46$ & $63.43 \pm 7.05$ & $1.859^{0.074}$ \\
\hline 4. & BMI $\left(\mathrm{kg} / \mathrm{m}^{2}\right)$ & $20.00 \pm 1.89$ & $20.64 \pm 1.21$ & $1.118^{0.274}$ \\
\hline 5. & Training (years) & $3.63 \pm 1.85$ & $3.71 \pm 1.43$ & $0.146^{0.885}$ \\
\hline 6. & Training (hours/week) & $24.88 \pm 7.71$ & $26.36 \pm 7.17$ & $0.545^{0.590}$ \\
\hline 7. & FM $(\mathrm{kg})$ & $6.85 \pm 4.22$ & $4.73 \pm 1.82$ & $-1.965^{0.033^{*}}$ \\
\hline 8. & FFM (kg) & $50.38 \pm 8.3$ & $58.36 \pm 6.18$ & $3.044^{0.005^{* *}}$ \\
\hline 9. & BCM $(\mathrm{kg})$ & $28.57 \pm 4.71$ & $33.10 \pm 3.51$ & $3.096^{0.004^{* *}}$ \\
\hline 10. & $\mathbf{M M}(\mathrm{kg})$ & $24.61 \pm 1.94$ & $28.82 \pm 2.50$ & $5.184^{0.000^{* *}}$ \\
\hline 11. & VO,max. (ml/kg/min.) & $43.23 \pm 9.03$ & $46.47 \pm 12.39$ & $0.799^{0.432}$ \\
\hline 12. & AverageAnaerobic Power (W) & $464.13 \pm 105.78$ & $596.79 \pm 135.76$ & $3.005^{0.006^{* *}}$ \\
\hline 13. & Fatigue Index(W/sec.) & $5.69 \pm 2.65$ & $5.66 \pm 2.96$ & $-0.158^{0.975}$ \\
\hline
\end{tabular}

Values are expressed as Mean $\pm S D .{ }^{*}$ represents $p \leq .05, * *$ represents $p \leq .01, B M I=$ Body mass index, $F M=$ Fat mass, $F F M=$ Fat free mass, $B C M=$ Body cell mass, $M M=$ Muscle mass, $V O_{2}$ max $=$ maximum aerobic capacity 
Table 2 shows Pearson's correlation coefficient between training experiences in years and duration in hours/week with various body composition and physiological variables in athletes practising team sports. None of the parameters were found to be significantly related with one another.

Table 2. Pearson's Correlation of training experience (years) and duration (hours/week) with the selected physical and physiological parameters of Indian Athletes of Team game $(n=16)$

\begin{tabular}{|c|c|c|c|c|c|c|c|}
\hline & $\begin{array}{l}\text { FM } \\
(\mathrm{kg})\end{array}$ & $\begin{array}{c}\text { FFM } \\
(\mathrm{kg})\end{array}$ & $\begin{array}{c}\text { BCM } \\
(\mathrm{kg})\end{array}$ & $\begin{array}{l}\text { MM } \\
(\mathrm{kg})\end{array}$ & $\begin{array}{c}\mathrm{VO}_{2} \max . \\
(\mathrm{ml} / \mathrm{kg} / \mathrm{min} .)\end{array}$ & $\begin{array}{l}\text { Average Anaerobic } \\
\text { Power (W) }\end{array}$ & $\begin{array}{l}\text { Fatigue Index } \\
\text { (W/sec.) }\end{array}$ \\
\hline $\begin{array}{l}\text { Training } \\
\text { (years) }\end{array}$ & $.174^{0.52}$ & $.089^{0.74}$ & $.067^{0.805}$ & $-.012^{0.96}$ & $.331^{0.211}$ & $.335^{0.24}$ & $.181^{0.54}$ \\
\hline $\begin{array}{l}\text { Training } \\
\text { (hrs/wk) }\end{array}$ & $.024^{0.93}$ & $.180^{0.50}$ & $.156^{0.57}$ & $-.358^{0.17}$ & $-.164^{0.543}$ & $-.309^{0.24}$ & $-.261^{0.33}$ \\
\hline
\end{tabular}

$F M=$ Fat mass, $F F M=$ Fat free mass, $B C M=$ Body cell mass, $M M=$ Muscle mass, $V \mathrm{O}_{2}$ max $=$ maximum aerobic capacity

Table 3 shows Pearson's correlation coef- in athletes participating in individual events. ficient between training experiences in years None of the parameters was found to be sigand duration in hours/ week with various nificantly related with one another. body composition and physiological variables

Table 3. Pearson's correlation of training experience (years) and duration (hours/week) with the selected physical and physiological parameters of Indian athletes of individual events $(n=14)$

\begin{tabular}{cccccccc}
\hline & $\begin{array}{c}\text { FM } \\
(\mathbf{k g})\end{array}$ & $\begin{array}{c}\text { FFM } \\
(\mathbf{k g})\end{array}$ & $\begin{array}{c}\text { BCM } \\
(\mathbf{k g})\end{array}$ & $\begin{array}{c}\text { MM } \\
(\mathbf{k g})\end{array}$ & $\begin{array}{c}\text { VO2max. } \\
(\mathbf{m l} / \mathbf{k g} / \mathbf{m i n})\end{array}$ & $\begin{array}{c}\text { Anaerobic Power } \\
(\mathbf{W})\end{array}$ & $\begin{array}{c}\text { Fatigue } \\
(\mathbf{W} / \mathbf{s e c})\end{array}$ \\
\hline $\begin{array}{c}\text { Training } \\
\text { (years) }\end{array}$ & $.279^{0.30}$ & $.303^{0.29}$ & $.301^{0.29}$ & $.330^{0.25}$ & $.063^{0.83}$ & $.335^{0.24}$ & $.181^{0.54}$ \\
$\begin{array}{c}\text { Training } \\
\text { (hrs/wk) }\end{array}$ & $.252^{0.38}$ & $.112^{0.70}$ & $.153^{0.60}$ & $-.087^{0.76}$ & $-.061^{0.84}$ & $-.144^{0.62}$ & $.035^{0.90}$ \\
\hline
\end{tabular}

$F M=$ Fat mass, $F F M=$ Fat free mass, $B C M=$ Body cell mass, $M M=$ Muscle mass, $V O_{2}$ max = maximum aerobic capacity

\section{DISCUSSION}

Body composition and physiological parameters can be possibly used to detect potentially talented athletes for a specific sports discipline. Hammami et al., (2012) observed that height \& weight operated as an influencing parameter of physical performance. In this study, the athletes participating in sprint event were found to be taller and heavier than footballers, although the difference was statistically insignificant. This may be attributed to the development of muscles in due course of time with the type of training undertaken by the sprinters.
Body composition was observed to play a vital role in estimation and prediction of performance of an elite player. Body composition goals vary between sports and among athletes within the same sports. For example, very high- intensity, very short duration track and field athletes benefit from high muscularity, but sprinters also benefit from a relatively low percentage of body fat while throwers (e.g., discus) benefit from having a percentage of body fat that is higher than that of most other athletes. Within a team sport, players may be distinguished by position and may have differ- 
ent body composition goals. The sprinters in the present study were found to possess significantly more fat free mass $(p<.01)$, body cell mass $(p<.01)$, muscle mass $(p<.01)$ and less fat mass $(p<.05)$ in comparison to their age and BMI matched football players, although all the mentioned body composition variables were found to be within normal range in both groups. These results are supported by the findings of Barbieri et al. (2017) who stated that sprinters with larger muscle mass and lower adiposity, less ectomorphy and more strength showed better performances. However, no significant correlation was established between fat mass (FM), fat free mass (FFM), and muscle mass (MM) of athletes of both groups with training years and hours per week. These observations were supported by previous results described by Rossi et al. (2017) where, it was stated that, in the off season i.e., the period of time after the conclusion of the season where athletes decrease sport specific skill work and start to focus on functional movement and strength development, no significant changes in body composition were found during mild training regimes regardless of a supervised or unsupervised conditioning training program.

Body Cell Mass (BCM) is a comparatively new approach for assessing body composition. $\mathrm{BCM}$ is the total mass of 'oxygen-exchanging, potassium-rich, glucose oxidizing, work-performing' cells of the body (Andreoli et al., 2003). In our study, no significant correlation was established between body cell mass (BCM) with training years and hours per week in either of the groups, contrasting to the previously conducted studies by Quieterio et al. (2008). They proposed that athletes training for more than 9 hours per week showed a greater level of BCM, i.e., more weekly training hours were associated with greater levels of BCM and lower levels of body fat. Also, a comparative study was done by Randáková (2005), on athletes and non-athletes. The obtained results showed high content of BCM due to regular training. The obtained results from this study could possibly be due to the small sample size. It is possible, that with larger sample size, body composition components might have shown correlation with the training status.

High level of aerobic capacity is indispensable for achieving success in many sports; therefore, the determination of $\mathrm{VO}_{2} \max$ is of special importance as it plays the key role in professional sports - it is the reflection of any athlete's physical capability (Rancovic et al., 2010). The $\mathrm{VO}_{2} \max$ indicates upper limit of body's ability to consume oxygen and maximum rate of energy released from oxidative process primarily. It is the highest rate at which an individual can intake oxygen during exercise and serves as the most popular index of aerobic fitness of sports persons (Armstrong, Weisman, 1994). In the current study, the footballers $(43.23 \pm 9.03 \mathrm{ml} / \mathrm{kg} / \mathrm{min})$ and sprinters $(46.47 \pm 12.39 \mathrm{ml} / \mathrm{kg} / \mathrm{min}$ ) had more or less the same $\mathrm{VO}_{2}$ max with a small range of variation and the difference was also found to be statistically insignificant. The reason could be that they were involved in a similar kind of training, which was based on strength endurance and explosive strength. It also implies that at least in our population overlaying regular resistance training to an endurance program or vice versa will not decrease performance in power events at the cost of endurance and vice versa.

A significant difference $(p<.01)$ was seen in average anaerobic power between the sprinters and footballers. This difference can be attributed to the nature of the activity done by the sprinters and to their larger muscle strength and not to faster muscle contractile properties. The sprinters continuously perform the activity with high explosiveness for pretty longer period of time than the footballers. Whereas in football, moves such as sprint during counter- 
attack situations, for example, highlight the anaerobic power. The maximum effort toward the goal or to intercept a move is notorious so that the anaerobic power becomes a very important variable during decisive moments of the match. Short accelerations are also highlighted in the anaerobic power and occur often during the game. The nature of the test was also favorable to sprinters and footballers as they go for sprinting activities during their workout. Degens et al. (2019) studied physiological aspects among four distinct athlete groups and found significant changes in anaerobic power in team and sprint athletes compared to the endurance athlete and non- athletes, similar to this study.

During intense exercise, muscle and blood lactate can rise to very high levels. Lactate accumulation causes an increased concentration of hydrogen ions and corresponding acidosis, a primary factor in muscle fatigue. Athletes with high fatigue index numbers should train to improve lactate tolerance in order to promote quicker recoveries from explosive bursts of speed and power. Mohor et al. (2005) observed that, fatigue or impaired performance in soccer happened through various phases of game, to operate in different periods of the match. In this study, the footballers and sprinters had more or less the same fatigue index values with a small range of variation and the difference was also found to be statistically insignificant. Also, no inter- correlation was obtained in any measurement between aerobic and anaerobic power values. However, Singh et al. (2014), analyzed fatigue levels in the Indian male hockey players and found significantly high fatigue levels in all of them with training. A similar study found several performance factors significantly associated with training-induced fatigue, in elite youth football players (Fitzpatrick et al., 2019). Also, Thorpe et al. (2016) cited significant changes in fatigue along with muscle soreness and sleep, during competitive season in football players, post 3-week training done by them. In same line, Tomlin and Wenger (2002) showed a negative relation between aerobic capacities with fatigue in athletes.

\section{LIMITATIONS}

This was a cross- sectional study and did not study the effects of specific training programs in pre- post condition, where the differences between the two groups may be to some extent attributable to genotypic differences (Erkine et al., 2014; Hagberg et al., 2001) rather than different training programs. Secondly, the sample size taken for the present study was relatively small. Larger sample sizes in future research will be essential to better comprehend training status for athletes participating in team sports as well as in individual events. Thirdly, training experience for these players was low, being a maximum of three years, which may have influenced the results, and hence deserve further research. Fourthly, indirect measurements were used to quantify both aerobic and anaerobic power among the players. Finally, all the measurements were made at the end of the competitive season.

\section{CONCLUSION}

This article considers the effect of sports specific training on the key parameters of fitness and attempts to relate these changes to the adaptations seen in the body's physiological systems with training. The physiological and body composition data of the present study can act as a basic frame of reference for monitoring and assigning or preparing the sports specific systematic training protocols for both footballers and sprinters.

\section{REFERENCES}

Aggarwala, J., Dhingra, M., \& Khan, A. (2018). Relationship between physiological and anthropometric characteristics in elite 
sports persons. International Journal of Yogic, Human Movement and Sports Sciences, Vol. 3 No. 1, pp. 1050-1053

Akoglu, H. (2018). User's guide to correlation coefficients. Turkish Journal of Emergency Medicine, 18(3), 91-93. https://doi. org/10.1016/j.tjem.2018.08.001

Andreoli, A., Melchiorri, G., Brozzi, M., Di Marco, A., Volpe, S. L., Garofano, P., \& De Lorenzo, A. (2003). Effect of different sports on body cell mass in highly trained athletes. Acta diabetologica, Vol. 40 No. 1, pp. s122-s125.

Armstrong, N., \& Welsman, J. R. (1994). Assessment and interpretation of aerobic fitness in children and adolescents. Exercise and sport sciences reviews, Vol. 22, pp. 435-476.

Barbieri, D., Zaccagni, L., Babic V, Rakovac, M., Misigoj-Durakovic, M., Gualdi-Russo, E., (2017) Body composition and size in sprint athletes. J Sports Med Phys Fitness, Vol. 57 No. 9, pp. 1142-1146.

Charmas, M., \& Gromisz, W. (2019). Effect of 12-week swimming training on body composition in young women. International Journal of Environmental Research and Public Health, Vol. 16 No. 3 pp. 346.

Degens, H., Stasiulis, A., Skurvydas, A., Statkeviciene, B., \& Venckunas, T. (2019). Physiological comparison between non-athletes, endurance, power and team athletes. European Journal of Applied Physiology, Vol. 119 No. 6, pp 1377-1386.

Erskine, RM., Williams, AG., Jones, DA., Stewart, CE., Degen, H., (2014). The individual and combined influence of ACE and ACTN3 genotypes on muscle phenotypes before and after strength training. Scand J Med Sci Sports, Vol. 24 No. 4, pp 642-648.

Fitzpatrick, J. F., Akenhead, R., Russell, M., Hicks, K. M., \& Hayes, P. R. (2019). Sensitivity and reproducibility of a fatigue response in elite youth football players. Science and Medi- cine in Football, Vol. 3 No. 3, pp. 214-220.

Genc, H., Cigerci, A. E., \& Sever, O. (2019). Effect of 8-week core training exercises on physical and physiological parameters of female handball players. Physical education of students, Vol. 23 No. 6, pp. 297-305.

Hagberg, JM., Moore, GE., Ferrell, RE, (2001). Specific genetic markers of endurance performance and VO2 max. Exerc Sport Sci Rev, Vol. 29 No. 1, pp 15-19.

Hammami, MA., Abderrahmane, AB., Nebigh, A., Moal, EL., Ounis, OB., Tabka, Z. and Zouhal H. (2012). Effects of a soccer season on anthropometric characteristics and physical fitness in elite young soccer players, Journal of Sports Sciences, Vol. I, pp. 1-8.

Heyward, V.H. and Stolarczyk, L.M. (1996). Applied body composition assessment. Champaign. Human Kinetics.

Lindwall, M., Johnson, U., \& Åström, Å. (2002). Världens bästa lag - om gruppdynamik inom idrotten. SISU Idrottsböcker: Farsta.

Manna, I., Khanna, G.L., and Dhara, P.C. (2010). Effect of Training on Physiological and Biochemical Variables of Soccer Players of Different Age Groups. Asian J Sports Med, Vol. 1 No. 1, pp. 5-22.

Mohr, M., Krustrup, P., \& Bangsbo, J. (2005). Fatigue in soccer: a brief review. Journal of Sports Sciences, 23(6), 593-599.

Quiterio, A. L., Carnero, E. A., Silva, A. M., Bright, B. C., \& Sardinha, L. B. (2009). Anthropometric models to predict appendicular lean soft tissue in adolescent athletes. Medicine \& Science in Sports \& Exercise, Vol. 41 No. 4, pp. 828-836.

Rampinini, E., Bishop D., Marcora, SM., Ferrari, Bravo, D., Sassi, R., Impellizzeri, FM. (2007). Validity of simple field tests as indicators of match-related physical performance in top-level professional soccer players. Int. $J$ Sports Med. Vol. 28, pp. 228-235.

Randáková, R. (2005). Effect of regular 
training on body composition and physical performance in young cross-country skiers: as compared with normal controls. Acta Universitatis Palackianae Olomucensis. Gymnica, Vol. 35 No.1.

Rancovic, G., Mutavdzic, V., Toskic, D., Preljevic, A., Kocic, M., Rankovic, GN., Damjanovic, N. (2010). Aerobic capacity as an indiactor in different kinds of sports. Bosn $\mathrm{J} \mathrm{Ba}$ sic Med Sci, Vol. 10 No.1, pp. 44-48.

Rossi, F. E., Landreth, A., Beam, S., Jones, T., Norton, L., \& Cholewa, J. M. (2017). The effects of a sports nutrition education intervention on nutritional status, sport nutrition knowledge, body composition, and performance during off season training in NCAA Division I baseball players. Journal of sports science \& medicine, Vol. 16 No. 1, pp. 60.

Singh, A., Sakshi, G., \& Singh, S. J. (2014). Effect of plyometric training on sand versus grass on muscle soreness and selected sportspecific performance variables in hockey players. Journal of Human Sport and Exercise, 9(1), 59-67.

Spencer, M., Bishop, D., Dawson, B., Goodman, C. (2005). Physiological and met- abolic responses of repeated-sprint activities: Specific to field-based team sports. Sports Med, Vol. 35, pp. 1025-1044.

Thorpe, R. T., Strudwick, A. J., Buchheit, M., Atkinson, G., Drust, B., \& Gregson, W. (2016). Tracking morning fatigue status across in-season training weeks in elite soccer players. International journal of sports physiology and performance, Vol. 11 No.7, pp. 947-952.

Thurlow, S., Taylor-Corill, G., Sahota, P. (2018). Effects of procedure, upright equilibrium time, sex and BMI on the precision of body fluid measurements using bioelectric impedance analysis. Eur J Clin Nutr, Vol. 72 No.1, pp. 148-53.

Tomlin, D. L., \& Wenger, H. A. (2002). The relationship between aerobic fitness, power maintenance and oxygen consumption during intense intermittent exercise. Journal of Science and Medicine in Sports, Vol. 5, pp. 194-203.

Zagatto, A.M., Beck, W.R., \& Gobatto, C.A. (2009). Validity of the running anaerobic sprint test for assessing anaerobic power and predicting short-distance performances. $J$ Strength Cond. Res. Vol. 23 No. 6, pp.1820-1827.

\section{Corresponding Author}

Dr. Subhra Chatterjee, PhD

Human Performance Laboratory Sports Authority of India New Delhi-110003

E-mail: subhra.presi@gmail.com 